\title{
First in-situ measurements of HF radar echoing targets
}

\author{
J. Moen, ${ }^{1,2}$ K. Oksavik, ${ }^{2,3}$ T. Abe,${ }^{4}$ M. Lester, ${ }^{5}$ Y. Saito, ${ }^{4}$ T. A. Bekkeng, ${ }^{1}$ \\ and K. S. Jacobsen ${ }^{1}$ \\ Received 17 February 2012; revised 9 March 2012; accepted 9 March 2012; published 13 April 2012.
}

[1] The sounding rocket Investigation of Cusp Irregularities 2 (ICI-2) was launched into the cusp ionosphere over Svalbard to investigate the production of decameter scale irregularities in the electron plasma associated with HF radar backscatter. The main mission objective was to obtain high-resolution measurements of decameter scale electron plasma irregularities and to quantify the growth rate for the gradient drift instability (GDI). At the $5.7 \mathrm{kHz}$ sampling rate of the absolute density measurements, ICI-2 has provided the first documentation in terms of absolute electron density measurements of how 10-m structures are located on km scale electron density gradients. ICI-2 traversed a cusp electron density structure created by ongoing soft precipitation. $10-\mathrm{m}$ scale irregularities were generated at $\mathrm{km}$ scale density gradients. The estimated growth time for the GDI process was 10-50 seconds. Citation: Moen, J., K. Oksavik, T. Abe, M. Lester, Y. Saito, T. A. Bekkeng, and K. S. Jacobsen (2012), First in-situ measurements of HF radar echoing targets, Geophys. Res. Lett., 39, L07104, doi:10.1029/2012GL051407.

\section{Introduction}

[2] Strong coherent HF radar backscatter is a well-known characteristic of the polar cusp ionosphere. Backscattering of the radar signals arises from irregularities transverse to the magnetic field at the Bragg scale, which is typically around 15 meter for coherent SuperDARN HF radars (half the radar wave length). Baker et al. [1986] reported an approximate agreement between radio scintillation observations and HF radar data, implying an occurrence relationship between irregularities of sub-kilometer scale responsible for scintillation and the decameter size radar targets in the cleft. The close correlation between regions of broad Doppler spectra and regions of cusp particle precipitation was first revealed by Baker et al. [1995]. The intimate relationship between HF radar cusp signatures and cusp auroral dynamics was documented by Rodger et al. [1995], Yeoman et al. [1997], Milan et al. [1999], and Moen et al. [2000], with particular focus on the co-location of the equatorward edge of the HF backscatter boundary and the equatorward edge of the cusp auroral boundary, for southward IMF conditions.

\footnotetext{
${ }^{1}$ Department of Physics, University of Oslo, Oslo, Norway.

${ }^{2}$ University Centre in Svalbard, Longyearbyen, Norway.

${ }^{3}$ Department of Physics and Technology, University of Bergen, Bergen, Norway.

${ }^{4}$ Institute of Space and Astronautical Science, Japan Aerospace Exploration Agency, Sagamihara, Japan.

${ }^{5}$ Department of Physics and Astronomy, University of Leicester, Leicester, UK.
}

Copyright 2012 by the American Geophysical Union. 0094-8276/12/2012GL051407
[3] In the case of a plasma density gradient in the direction of plasma motion the gradient drift instability (GDI) is regarded as the dominant mode for driving the plasma unstable in the F region auroral ionosphere [e.g., Ossakow and Chaturvedi, 1979; Basu et al., 1994; Tsunoda, 1988]. Moen et al. [2002] estimated the zero order GDI growth rate based on tomographic imaging of the density gradient and radar flow measurements, and they concluded that the calculated growth time was too slow to explain the close co-location of the auroral cusp and the HF radar cusp boundary. They proposed that the initial source of the decameter scale features responsible for the backscatter may result from fine structure within the precipitation itself, or alternatively, from cascade of unstable intermediate-scale gradients not resolved by the radio tomography technique. Moen et al. [2002] thus pointed out the need for highresolution measurements in order to assess the role of the GDI process.

[4] The Norwegian ICI-series of rockets is aimed at isolating different types of plasma instabilities in the $\mathrm{F}$ region cusp/polar cap ionosphere. This letter is devoted to the first direct measurements of cusp HF-backscatter targets by the ICI-2 sounding rocket.

\section{Instrumentation}

[5] This work is based on the following two experiments onboard the ICI-2 rocket:

[6] 1. Four-Needle Langmuir Probe (4-NLP): The experiment consists of four identical cylindrical probes with a diameter of $0.5 \mathrm{~mm}$ and a length of $25 \mathrm{~mm}$. In the topside ionosphere the Debye length (plasma charge shielding distance) is typically $1 \mathrm{~cm}$, i.e., much larger than the probe diameter and plasma shielding effects can be neglected. The four probes were biased at $2.5 \mathrm{~V}, 4.0 \mathrm{~V}, 5.5 \mathrm{~V}$, and $10 \mathrm{~V}$ with respect to the rocket potential, in order to measure the saturated electron currents [Bekkeng et al., 2010]. A crucial feature of the 4-NLP technique is that $d I_{e}^{2} / d V_{p}$ is a function of electron density squared $\left(\mathrm{n}_{\mathrm{e}}^{2}\right)$, independent of the electron temperature $T_{e}$ and the spacecraft potential [Jacobsen et al., 2010], which allowed us to sample the absolute electron density at a rate of $5.7 \mathrm{kHz}$ which equals sub-meter scale resolution.

[7] 2. Low Energy Particle spectrometer (LEP-ESA): LEP-ESA measures the electron distribution function in the energy range $0.01-7.2 \mathrm{keV}$. The sensor is a top-hat type Electro Static Analyzer (ESA) with a pair of flat disks, which work as a collimator at the entrance, and toroidal electrodes inside. The instrument has a $360^{\circ}$ field-of-view with a pitch angle resolution of $22.5^{\circ}$. The time resolution was $22.1 \mathrm{~ms}$ for 32 energy steps, corresponding to $\sim 30 \mathrm{~m}$ spatial resolution during the flight.

[8] Of ground-based instrumentation we will present observations from the $630.0 \mathrm{~nm}$ all-sky imager at the Kjell 


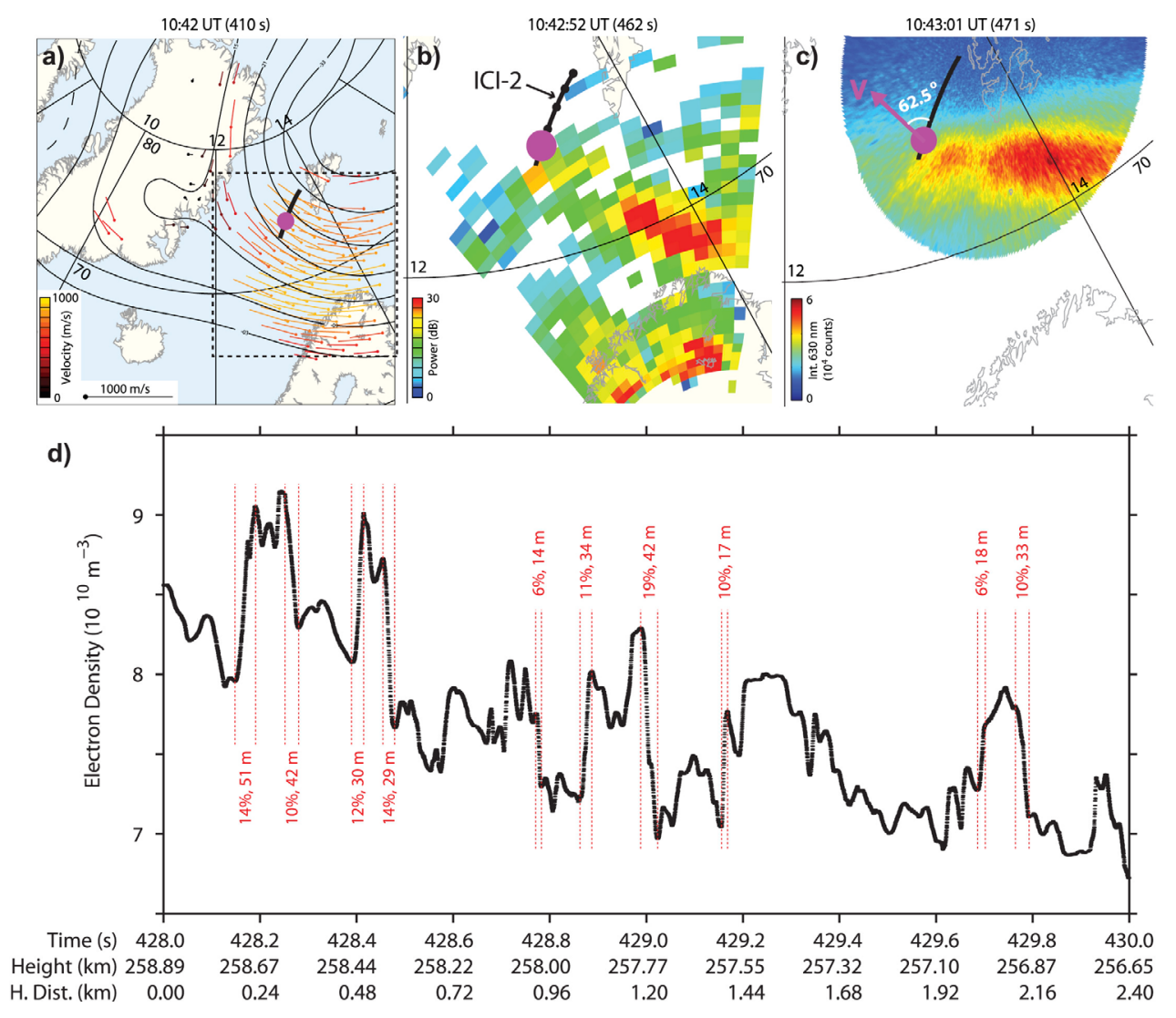

Figure 1. (a) SuperDARN convection map with the ICI-2 flight overlaid. The coordinates are magnetic latitude and magnetic local time (MLAT, MLT). The black curve southwest of Spitsbergen represents the rocket trajectory above $200 \mathrm{~km}$ altitude. The rocket position at 10:42 UT (410 s flight time) is marked by the pink dot on the trajectory. (b) HF backscatter power recorded by the SuperDARN Hankasalmi radar in Finland. ICI-2 encountered the poleward boundary of the HF backscatter region. (c) A $630.0 \mathrm{~nm}$ all-sky image during the encounter of HF backscatter irregularities. The large-scale plasma flow seen by SuperDARN is indicated by a pink arrow, and it made a $62.5^{\circ}$ angle with the anti-parallel of the rocket trajectory. (d) A zoom-in of $2 \mathrm{~s}$ high-resolution electron density data, where we have marked decameter scale plasma gradients in red color. The altitude of the rocket payload, including horizontal distance traveled after $428 \mathrm{~s}$, is shown as text along the time axis.

Henriksen Observatory (KHO) at Longyearbyen, Svalbard, and the SuperDARN Hankasalmi HF radar in Finland, which operated two experimental modes simultaneously [Lester et al., 2004]. The radar frequency was $12.4 \mathrm{MHz}$, and one channel made a $48 \mathrm{~s}$ sweep through all 16 beam directions at $45 \mathrm{~km}$ range resolution, and the other channel made measurements every $3 \mathrm{~s}$ at $15 \mathrm{~km}$ range resolution along beam 7. SuperDARN convection patterns were created using the technique of Ruohoniemi and Baker [1998]. This technique involves both median filtering of noisy/ marginal Doppler velocities, binning of the remaining data into equal area cells, estimation of plasma flow velocities in areas of poor data coverage using model patterns based on the given IMF orientation, and a spherical harmonic fit to obtain flow vectors every two minutes in a $110 \times 110 \mathrm{~km}$ grid. These data points were then interpolated in time and space along the rocket trajectory to obtain flow vectors parallel and perpendicular to the rocket track.

\section{Observations}

[9] ICI-2 was launched from SvalRak at Ny-Ålesund at 10:35.10 UT on 05 December 2008, and it reached an apogee of $330 \mathrm{~km} 302 \mathrm{~s}$ later. Figure 1a shows the SuperDARN convection pattern at 10:42.00 UT (410 s flight time), which is representative for the large-scale ion flow during the entire flight. The black curve represents the rocket trajectory, and the pink dot marks the rocket position at the time corresponding to the duration of the radar data. ICI-2 encountered the poleward boundary of the cusp convection channel in the dusk cell around 13:40 MLT. Lorentzen et al. [2010] reported an overview of the geophysical situation for the ICI-2 flight, with emphasis on the creation of polar cap patches in association with poleward moving auroral forms. ICI-2 intersected a poleward moving auroral form/patch structure during the up-leg, and descended onto an inverted-V structure near the poleward boundary of the cusp proper, also associated with elevated electron density. Both density structures were associated with decameter scale irregularities and they were both associated with ongoing electron precipitation [Lorentzen et al., 2010]. The LEP-ESA experiment was not yet turned on during the first patch encounter and we therefore focus on the latter density structure. Figures $1 \mathrm{~b}$ demonstrates where ICI-2 encountered the poleward HF backscatter boundary. Comparing this with Figure 1c, the poleward cusp auroral boundary was located poleward of the cusp backscatter boundary. Figure 1d shows $2 \mathrm{~s}$ of 

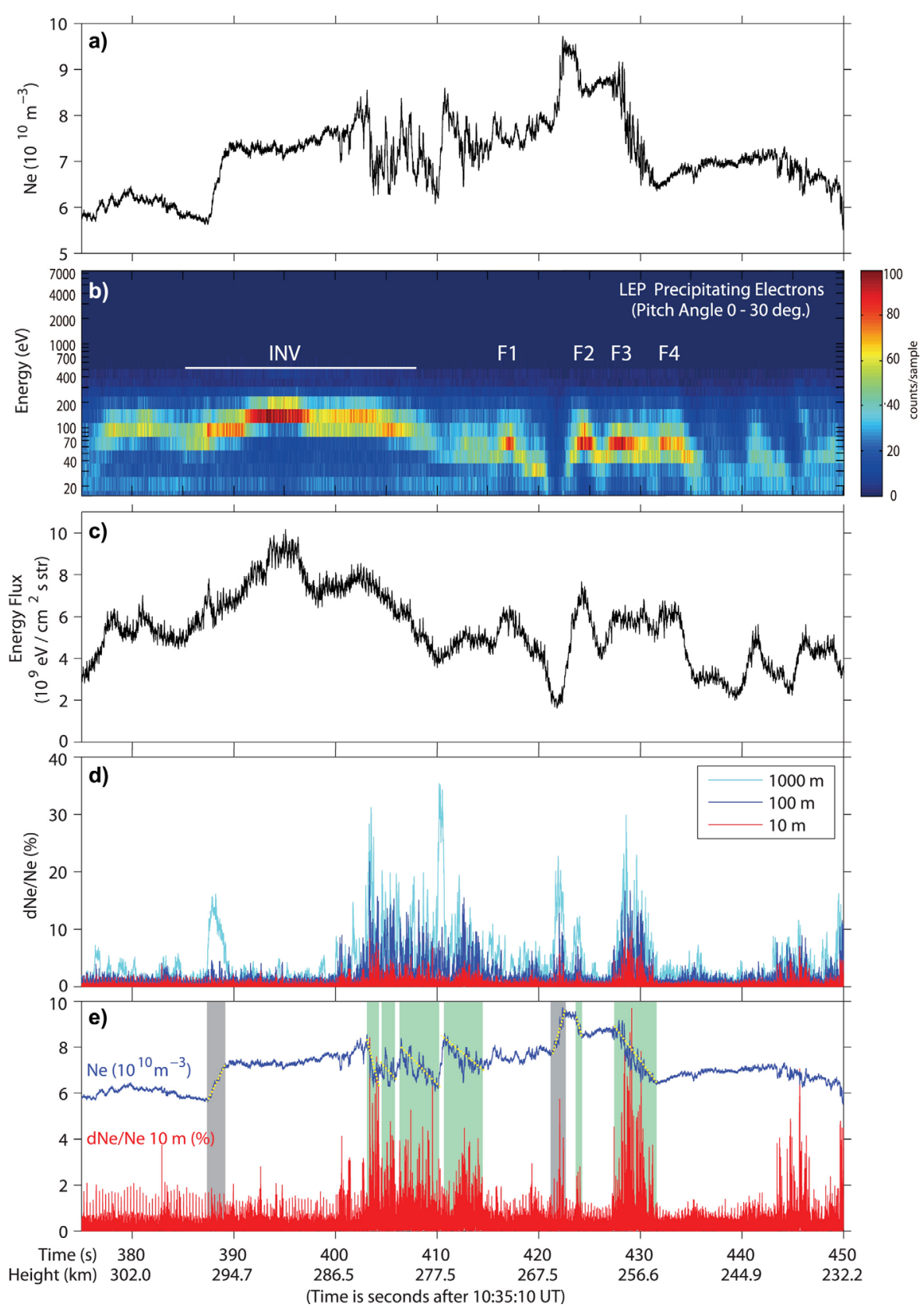

Figure 2. (a) Absolute electron density along the ICI-2 trajectory at 375-450 s flight time. (b) A spectrogram of the precipitating $0.01-7.2 \mathrm{keV}$ electron flux at $0-30^{\circ}$ pitch angle, and (c) the corresponding electron energy flux. (d) Electron plasma density fluctuations at wavelengths of $10 \mathrm{~m}, 100 \mathrm{~m}$, and $1000 \mathrm{~m}$. (e) The electron density (blue curve) is plotted above the $10 \mathrm{~m}$ fluctuation levels (red). The dashed yellow lines mark the slope of the electron density curve; positive slopes (stable to GDI growth) are highlighted with gray shading, and negative slopes (unstable to GDI growth) are highlighted with green shading. For the intervals shaded in green there is a clear match between negative density gradients and formation of plasma irregularities at $10 \mathrm{~m}$ scale. The altitude of the rocket payload is shown as text along the time axis.

high-resolution electron density data (428-430 s flight time). The density was 7-9 $\times 10^{10} \mathrm{~m}^{-3}$ during this interval. Assuming that the spatial plasma structures are frozen into the $\mathrm{E} \times \mathrm{B}$ plasma drift, we estimate the spatial scale of the density gradients and the corresponding irregularity amplitude $\left(\Delta N_{e} / N_{e}\right)$. Numbers are annotated for a selection of decameter scale plasma gradients marked out by vertical dashed red lines in Figure 1d.

[10] Figure 2a presents the electron density acquired during the $375-450 \mathrm{~s}$ interval of the flight, corresponding to the encounter of the poleward boundary of HF backscatter. ICI-2 traversed an electron density structure at 387-432 s, corresponding to the cusp electron precipitation region shown in Figures $2 \mathrm{~b}$ and $2 \mathrm{c}$. The rocket horizontal velocity was $1 \mathrm{~km} / \mathrm{s}$, i.e., the spatial dimension of the cut was $\sim 50 \mathrm{~km}$. Figure $2 \mathrm{~d}$ shows the irregularity amplitudes for $1 \mathrm{~km}, 100 \mathrm{~m}$ and $10 \mathrm{~m}$ scale structures in turquoise, blue and red color, respectively. In Figure 2e, the blue curve is the electron density versus time of flight (the same as in Figure 2a) and the red curve represents the irregularity amplitudes for the 
$10-\mathrm{m}$ structures (same as the red curve in the above Figure 2d). Yellow dotted lines on top of the electron density curve delineate the $\mathrm{km}$ scale gradients, and gray shading (positive gradients) and green shading (negative gradients) is used to ease the comparison with $10 \mathrm{~m}$ irregularities (to be discussed in detail below). Note that the onset of significant density irregularities was detected around $400 \mathrm{~s}$ flight time (10:41:50 UT) in Figure 2e. This is immediately equatorward of the electron precipitation boundary (Figure 2b) but $\sim 1$ minute prior to the ICI-2 encounter of the poleward HF radar backscatter boundary in Figure 1b. Since we do not know the exact propagation path of SuperDARN radio waves, this is within the uncertainty of $45 \mathrm{~km}$ wide range gates.

\section{Discussion}

[11] Moen et al. [2002] proposed that fine structures in the electron precipitation could give rise to decameter scale irregularities. Indeed there are many sub-structures within the auroral band. ICI-2 first encountered a $30 \mathrm{~km}$ wide inverted-V structure marked INV in Figure 2b, equatorward of which there are four prominent $\sim 3 \mathrm{~km}$ wide beam filaments (F1-4) that also have an inverted-V shape. Comparing Figures $2 \mathrm{~b}$ and $2 \mathrm{e}$ we note that the most intense part of INV and the entire F1, F2 and F4 electron fluxes were not associated with decameter scale irregularities. The only exception is F3 that was associated with a steep plasma gradient on the equatorward side. Thus, it seems less likely that the electron beam filaments directly had generated decameter scale irregularities in this case, and the focus is directed towards the role of $\mathrm{km}$ scale density gradients.

[12] From Figure $2 \mathrm{~d}$ it is evident that all decameter scale irregularities had spawned down from $\mathrm{km}$ scale structures. The life time of $10 \mathrm{~km}$ scale structures in the $\mathrm{F} 2$ region may be many hours in the dark hemisphere [Vickrey and Kelley, 1982]. The $200 \mathrm{eV}$ energy cusp precipitation will not affect the E-region conductivity significantly, and the $\mathrm{km}$ scale structures may therefore propagate great distances from their source. However, there is quite good correlation between the variations in the electron density and the electron precipitation for the $\sim 50 \mathrm{~km}$ wide electron density ridge at 387-432 s (cf. Figures $2 \mathrm{a}$ and $2 \mathrm{c}$ ). From the optical recordings we know that the auroral activity intensified around 10:38 UT, i.e., four minutes prior to the ICI-2 encounter. It is therefore likely that the electron density ridge is a spatial structure modulated by particle impact electron precipitation.

[13] The poleward auroral boundary drifted poleward when the rocket traversed through it. In Figure 2e we have marked the density slopes associated with $>4 \%$ decameter scale irregularities (gray and green shading). The GDI process is unstable only when there is a flow component along the density gradient [Ossakow and Chaturvedi, 1979]. For an east-west extended plasma structure moving poleward, the GDI process should be stable on the poleward edge of the density structure ( $\sim 388 \mathrm{~s}$, gray shading) which is the case. The GDI should be unstable for poleward density gradients (density decrease with time), which is also the case (e.g., 403-414 s and 428-431 s, green shading). However, there is one exception around $422 \mathrm{~s}$ (gray shading) where irregularities have formed on an equatorward gradient as well. Since the predominant plasma flow was westward across the rocket trajectory (see Figure 1a), we cannot rule out zonal plasma gradients onto which the GDI process was active.
[14] We have also investigated the potential role of the Kelvin Helmholtz Instability (KHI) in the two-step process suggested by Carlson et al. [2007] where the GDI generate the decameter irregularities. That result will be published elsewhere, but their mechanism did not apply for the case presented here.

[15] Let us now consider the linear growth rate of the GDI process in the F-region ionosphere given by:

$$
\gamma_{0}=\frac{V_{0}}{L}
$$

where $V_{0}$ is the drift relative to the neutral gas, and $L$ is the gradient scale length [Tsunoda, 1988] given by:

$$
L=\left[\frac{1}{N_{e o}} \frac{\Delta N_{e}}{\Delta x}\right]^{-1}
$$

We can use ICI-2 electron density data to determine the plasma density gradient. From 427.5 to $431.0 \mathrm{~s}$ the electron density changed from $\mathrm{N}_{\mathrm{e}}=8.75 \times 10^{10} \mathrm{~m}^{-3}$ to $\mathrm{N}_{\mathrm{e} 0}=$ $6.50 \times 10^{10} \mathrm{~m}^{-3}$, i.e., $\Delta \mathrm{N}_{\mathrm{e}}=2.25 \times 10^{10} \mathrm{~m}^{-3}$. According to SuperDARN the plasma flow speed around $430 \mathrm{~s}$ was $547 \mathrm{~m} / \mathrm{s}$ in a direction making a $62.5^{\circ}$ angle with the anti-parallel of the rocket trajectory, see Figure $1 \mathrm{c}$. In other words, the plasma flow can be split into two components; one component of $485 \mathrm{~m} / \mathrm{s}$ perpendicular to the track and into the polar cap, and one component of $252 \mathrm{~m} / \mathrm{s}$ anti-parallel to the rocket motion. Because the electron density gradient perpendicular to the rocket track is unknown, we choose to concentrate on the measured plasma flow along the rocket track, i.e., we set $\mathrm{V}_{0}=252 \mathrm{~m} / \mathrm{s}$. The geographic coordinates of the rocket shows that it travelled a horizontal distance of $3318 \mathrm{~m}$ in $3.5 \mathrm{~s}$. In that time the plasma moved $882 \mathrm{~m}$ towards the rocket, which gives a net horizontal scale length $\Delta \mathrm{x}=4200 \mathrm{~m}$, a gradient scale length of $\mathrm{L}=1.2 \times 10^{4} \mathrm{~m}$, a growth rate of $\gamma_{0}=0.021 \mathrm{~s}^{-1}$, and a growth time of $47.6 \mathrm{~s}$.

\section{Summary and Concluding Remarks}

[16] The ICI-2 rocket was successfully launched to observe $\mathrm{HF}$ radar echoing targets The unprecedented resolution of our electron density data allowed the first direct observation of HF backscatter targets, and it enabled us to identify the targets exactly where they are located relative to $\mathrm{km}$ scale gradients. Figure 2e delineates that decameter scale irregularities had spawned down from $\mathrm{km}$ scale gradients. The $\mathrm{km}$ scale structures were most likely modulated by auroral particle precipitation, which is consistent with Kelley et al. [1982], who from sounding rocket data also provided evidence that soft particle precipitation is an important source of large-scale irregularities $(>10 \mathrm{~km})$ onto which plasma instabilities can operate.

[17] The calculated growth time for the GDI process was found to be $47.6 \mathrm{~s}$ in the direction along the rocket track. However, we also notice that there was significant plasma flow in the direction perpendicular to the rocket track. If a similar density gradient existed perpendicular to the direction of maximum plasma flow, the growth time would reduce to only $10 \mathrm{~s}$. This is $15-70$ times faster than the 12 minutes growth time estimated by Moen et al. [2002] based on ground observations. This makes us conclude that in the cusp auroral 
ionosphere there are sufficiently steep plasma gradients onto which the GDI process can operate efficiently. We have initiated modeling work to assess whether the $\mathrm{km}$ scale electron beams can modulate these plasma gradients. The ICI-3 rocket was launched in December 2011 to investigate the potential role of the flow shear instability, and we will launch ICI-4 in 2013 to build more confidence on the controlling factors for HF backscatter irregularity generation.

[18] Acknowledgments. Thanks to the Norwegian Polar Institute for hosting the University of Oslo's optical instrumentation at Ny-Ålesund, Svalbard. SuperDARN operations at the University of Leicester were supported by STFC grant PP/E007929/1, and ML is funded by STFC grant $\mathrm{ST} / \mathrm{H} 002480 / 1$. This project has also been sponsored by the Research Council of Norway, Andoya Rocket Range, the Air Force Office of Scientific Research, Air Force Material Command, USAF, under grant FA8655-101-3003, and COST action ES0803.

[19] The Editor thanks two anonymous reviewers for their assistance in evaluating this paper.

\section{References}

Baker, K. B., R. A. Greenwald, A. D. M. Walker, P. F. Bythrow, L. J. Zanetti, T. A. Potemra, D. A. Hardy, F. J. Rich, and C. L. Rino (1986), A case study of plasma processes in the dayside cleft, J. Geophys. Res., 91(A3), 3130-3144, doi:10.1029/JA091iA03p03130.

Baker, K. B., J. R. Dudeney, R. A. Greenwald, M. Pinnock, P. T. Newell, A. S. Rodger, N. Mattin, and C.-I. Meng (1995), HF radar signatures of the cusp and low-latitude boundary layer, J. Geophys. Res., 100(A5), 7671-7695, doi:10.1029/94JA01481.

Basu, S., S. Basu, P. K. Chaturvedi, and C. M. Bryant Jr. (1994), Irregularity structures in the cusp/cleft and polar cap regions, Radio Sci., 29(1), 195-207, doi:10.1029/93RS01515.

Bekkeng, T. A., K. S. Jacobsen, J. K. Bekkeng, A. Pedersen, T. Lindem, J.-P. Lebreton, and J. I. Moen (2010), Design of a multi-needle Langmuir probe system, Meas. Sci. Technol., 21, 085903, doi:10.1088/0957-0233/ 21/8/085903.

Carlson, H. C., T. Pedersen, S. Basu, M. Keskinen, and J. Moen (2007), Case for a new process, not mechanism, for cusp irregularity production, J. Geophys. Res., 112, A11304, doi:10.1029/2007JA012384.

Jacobsen, K. S., A. Pedersen, J. I. Moen, and T. A. Bekkeng (2010), A new Langmuir probe concept for rapid sampling of space plasma electron density, Meas. Sci. Technol., 21, 085902, doi:10.1088/0957-0233/21/8/ 085902 .

Kelley, M. C., J. F. Vickrey, C. W. Carlson, and R. Torbert (1982), On the origin and spatial extent of high-latitude $\mathrm{F}$ region irregularities, J. Geophys. Res., 87(A6), 4469-4475, doi:10.1029/JA087iA06p04469.
Lester, M., et al. (2004), Stereo CUTLASS-A new capability for the SuperDARN radars, Ann. Geophys., 22, 459-473, doi:10.5194/angeo22-459-2004.

Lorentzen, D. A., J. Moen, K. Oksavik, F. Sigernes, Y. Saito, and M. G. Johnsen (2010), In situ measurement of a newly created polar cap patch, J. Geophys. Res., 115, A12323, doi:10.1029/2010JA015710.

Milan, S. E., M. Lester, S. W. H. Cowley, J. Moen, P. E. Sandholt, and C. J. Owen (1999), Meridian-scanning photometer, coherent HF radar, and magnetometer observations of the cusp: A case study, Ann. Geophys., 17, 159-172, doi:10.1007/s00585-999-0159-5.

Moen, J., H. C. Carlson, S. E. Milan, N. Shumilov, B. Lybekk, P. E. Sandholt, and M. Lester (2000), On the collocation between dayside auroral activity and coherent HF radar backscatter, Ann. Geophys., 18, 1531-1549, doi:10.1007/s00585-001-1531-2.

Moen, J., I. K. Walker, L. Kersley, and S. E. Milan (2002), On the generation of cusp HF backscatter irregularities, J. Geophys. Res., 107(A4), 1044, doi:10.1029/2001JA000111.

Ossakow, S. L., and P. K. Chaturvedi (1979), Current convective instability in the diffuse aurora, Geophys. Res. Lett., 6(4), 332-334, doi:10.1029/ GL006i004p00332.

Rodger, A. S., S. B. Mende, T. J. Rosenberg, and K. B. Baker (1995), Simultaneous optical and HF radar observations of the ionospheric cusp, Geophys. Res. Lett., 22(15), 2045-2048, doi:10.1029/95GL01797.

Ruohoniemi, J. M., and K. B. Baker (1998), Large-scale imaging of highlatitude convection with Super Dual Auroral Radar Network HF radar observations, J. Geophys. Res., 103(A9), 20,797-20,811, doi:10.1029/ 98JA01288.

Tsunoda, R. T. (1988), High-latitude F region irregularities: A review and synthesis, Rev. Geophys., 26(4), 719-760, doi:10.1029/RG026i004p00719.

Vickrey, J. F., and M. C. Kelley (1982), The effects of a conducting E layer on classical F region cross-field plasma diffusion, J. Geophys. Res. 87(A6), 4461-4468, doi:10.1029/JA087iA06p04461.

Yeoman, T. K., M. Lester, S. W. H. Cowley, S. E. Milan, J. Moen, and P. E. Sandholt (1997), Simultaneous observations of the cusp in optical, DMSP and HF radar data, Geophys. Res. Lett., 24(17), 2251-2254, doi:10.1029/97GL02072.

T. Abe and Y. Saito, Institute of Space and Astronautical Science, Japan Aerospace Exploration Agency, 3-1-1 Yoshinodai, Sagamihara, Kanagawa 229-8510, Japan.

T. A. Bekkeng, K. S. Jacobsen, and J. Moen, Department of Physics, University of Oslo, PO Box 1048 Blindern, N-0316 Oslo, Norway. (jmoen@fys.uio.no)

M. Lester, Department of Physics and Astronomy, University of Leicester, Leicester LE1 7RH, UK.

K. Oksavik, Department of Physics and Technology, University of Bergen, PO Box 7803, N-5020 Bergen, Norway. 